\title{
Secondary Metabolites From Different Extractives of Stereospermum suaveolens
}

\section{Fatema Begum ${ }^{1}$, Mohammad Rashedul Haque ${ }^{1}$, Kazi Sharmin Nahar $^{2}$ and Mohammad Abdur Rashid ${ }^{1}$}

\author{
${ }^{1}$ Phytochemical Research Laboratory, Department of Pharmaceutical Chemistry, Faculty of Pharmacy, \\ University of Dhaka, Dhaka-1000, Bangladesh \\ ${ }^{2}$ Department of Pharmacy, King's College London, Franklin-Wilkins Building, 150 Stamford Street, \\ London SE1 9NH, United Kingdom
}

Received: May 25, 2014; Accepted: June 17, 2014; Published (web): June 29, 2014

\begin{abstract}
The methanol extract of leaves and bark of Stereospermum suaveolens has been subjected to repeated-chromatographic separation and purification processes to isolate the secondary metabolites. A total of seven compounds have been isolated from the plant, which were identified as fridelin (1), $\beta$-sitosterone (stigmast-5en-3-one) (2), stigmasterol (3), 3,4-dimethoxy cis-caffeic acid (4), 3 $\beta$-friedelanol (5), $\beta$-amyrone (6) and glyceryl tricaprate (7). The structures of the isolated compounds were elucidated by extensive NMR studies.
\end{abstract}

Key words: Bignoniaceae, $\beta$-amyrone, chromatography, fridelin, NMR, Stereospermum suaveolens

\section{INTRODUCTION}

Stereospermum suaveolens (Roxb.) (Bengali name: Atkapali, paruli gachh; English name: Trumpet; Common name: Patala) is a plant from the Bignoniaceae family. S. suaveolens is a medicinal plant species native to India, Bangladesh and Myanmar. ${ }^{1}$ The plant is widely distributed in the subhimalayan tract and outer hills, central India, western Peninsula, Myanmar, Bangladesh and the English forest. The family Bignoniaceae having about 100 genera with 800 species, is known for their antimicrobial, antiprotozoal, and anti-inflammatory properties. $^{2,3}$ Moreover, bark, flowers, roots and leaves of S. suaveolens are used by traditional healers in rural communities and pharmaceutical companies for remedies of diseases like vomiting, eructation, piles, acidity, diarrhoea, gonorrhoea, loss of taste, malaria and other fevers. ${ }^{1}$ It is reputed for its antipyretic property and is also useful in excessive thirst, cough and asthma. ${ }^{4}$ S. suaveolens root bark is an ingredient of Dasmula, an Ayurvedic formulation. Decoction of roots is used in intermittent, puerperal

Correspondence to: Mohammad A. Rashid

Tel: +880-2-9661900-73 Extn.-8137, Fax: 880-2-8615583

E-mail: rashidma@du.ac.bd

Dhaka Univ. J. Pharm. Sci. 13(1): 31-36, 2014 (June) fevers and infections of the brain. Stem bark is diuretic and tonic. Flowers are given with honey to treat cough. ${ }^{5}$ Previous chemical investigations of this plant led to the isolation of lapachol, dinatin, dinatin7- glucuroniside and sitosterol. ${ }^{6,7}$ Both the timber and the root heartwood of $S$. suaveolens were found to contain lapachol, elicitor of contact dermatitis. ${ }^{8-10}$ Studies conducted with $S$. suaveolens (Syn. S. chelonoides DC) provided two new quinones, stereochenols $\mathrm{A}$ and $\mathrm{B}^{11}$ along with sterekunthal $\mathrm{B}$ and sterequinone $\mathrm{C}$, previously known from $S$. kunthianum $^{12}$ and S. personatum. ${ }^{13}$

As a part of our ongoing research on medicinal plants of Bangladesh, ${ }^{14,15}$ we studied S. suaveolens and herein, report seven compounds for the first time from this plant.

\section{MATERIALS AND METHODS}

General experimental procedure. NMR spectra were recorded using Bruker AMX-400 and AMX500 instrument in deuterated chloroform and the $\delta$ values for ${ }^{1} \mathrm{H}$ were referenced relative to the residual non-deuterated solvent signal. RV10 Basic (IKA, Germany) was used for rotary evaporation. For vacuum liquid chromatography (VLC) and gel 
permeation chromatography columns were packed by Kieselgel 60H (mesh 70-230) and Sephadex (LH-20), respectively. Analytical thin layer chromatography (TLC) was performed on precoated plates (TLC Silica gel $60 \mathrm{~F}_{254}$-Merck $\mathrm{KGaA}$ ) and UV light \& vanillin $/ \mathrm{H}_{2} \mathrm{SO}_{4}$ reagents were used to visualize the spots. All other chemicals, solvents and reagents were of analytical grade.

Plant materials. The leaves and bark of $S$. suaveolens were collected from Baldha garden, Dhaka in the month of June, 2012 and was identified by the experts of Bangladesh National Herbarium where a voucher specimen (DACB Accession number- 37882) representing this collection has been deposited.

Extraction and isolation. The air dried powdered material $(743 \mathrm{~g})$ was extracted with $2.5 \mathrm{~L}$ of methanol in a large conical flask at room temperature for 10 days with occasional shaking and stirring. The whole mixture was then filtered off through a filter paper and the filtrate obtained was concentrated at $40{ }^{\circ} \mathrm{C}$ with a rotary evaporator (yield, $2.7 \%)$. A portion $(19 \mathrm{~g})$ of the concentrated methanol extract was fractionated by the modified Kupchan partitioning protocol ${ }^{16}$ to afford petroleum ether (2.84 $\mathrm{g})$, dichloromethane $(3.37 \mathrm{~g})$, ethyl acetate $(3.86 \mathrm{~g}$ ) and aqueous $(8.05 \mathrm{~g})$ soluble materials.

The petroleum ether soluble partitionate $(2.50 \mathrm{~g})$ was subjected to column chromatography over silica gel (Kieselgel, mesh 70-230) using mixtures of petroleum ether and ethyl acetate with increasing polarities and a total of 79 fractions (each $15 \mathrm{ml}$ ) were collected. Depending on the TLC behavior, fractions 56-60 were mixed and subjected to preparative thin layer chromatography (PTLC) using $10 \%$ ethyl acetate in dichloromethane to yield stigmasterol (3).

Similarly the dichloromethane soluble materials $(3.37 \mathrm{~g})$ were fractionated by column chromatography over silica gel (Kieselgel, mesh 70230) using dichloromethane and ethyl acetate mixtures of varying polarities to provide a total of 130 fractions (each $15 \mathrm{ml}$ ). Fractions 66-72 were bulked and subjected to PTLC (Kieselgel $60 \mathrm{~F}_{254}$ ) using 7\% ethyl acetate in dichloromethane with few drops of acetic acid and 3,4-dimethoxy-cis-caffeic acid (4) was obtained.

A portion of the crude methanolic extract (10.8 g) was subjected to vacuum liquid chromatography (VLC) over silica gel 60H (100-200 mesh). The column was eluted with petroleum ether, followed by mixtures of petroleum ether and ethyl acetate, ethyl acetate and finally ethyl acetate and methanol with increasing polarities. On the basis of TLC, fractions 4 - 8 eluted with $8,12,15,20$ and $25 \%$ ethyl acetate in petroleum ether, respectively were subjected to further investigation. Further purification of fraction number 5 by PTLC over silica gel (Kieselgel $60 \mathrm{~F}_{254}$ ) using 7\% ethyl acetate in petroleum ether yielded fridelin (1) and stigmast-5-en-3-one or $\beta$-sitosterone (2).

VLC fractions $4,6,7$ and 8 were mixed and purified by column chromatography over silica gel (Kieselgel, mesh 70-230) for rapid fractionation using petroleum ether and ethyl acetate mixtures of increasing polarities. A total of 207 fractions (each 15 $\mathrm{ml}$ ) were collected. On the basis of TLC, fractions 32-37 were combined and the mixture was subjected to PTLC using $8 \%$ ethyl acetate in petroleum ether and gave $3 \beta$-friedelanol (5) and glyceryl tricaprate (7) were obtained.

Another aliquot $(31.5 \mathrm{~g})$ of crude methanolic extract was also subjected to partitioning by petroleum ether, chloroform and ethyl acetate. A portion of the chloroform soluble partitionate $(5.62 \mathrm{~g})$ was purified by column chromatography over silica gel (Kieselgel, mesh 70-230) using petroleum ether and ethyl acetate mixtures of increasing polarities. On the basis of TLC behavior, fractions 9-22 were mixed and subjected to PTLC using 0.5\% ethyl acetate in petroleum ether to yield $\beta$-amyrone (6).

Properties of isolated compounds. Fridelin (1): (Syn. Friedelan-3-one, 3-Friedelanone); Colorless gum; ${ }^{1} \mathrm{H}$ NMR $\left(400 \mathrm{MHz}, \mathrm{CDCl}_{3}\right): \delta 0.72(3 \mathrm{H}, \mathrm{s}$, Me-5), 0.87 (3H, s, Me-9), 0.88 (3H, br. s, Me-4), $0.95\left(3 \mathrm{H}, \mathrm{s}, \mathrm{Me}_{\mathrm{b}}-20\right), 0.99\left(3 \mathrm{H}, \mathrm{s}, \mathrm{Me}_{\mathrm{a}}-20\right), 1.01(3 \mathrm{H}$, s, Me-14), 1.05 (3H, s, Me-13), 1.18 (3H, s, Me-17), $1.71\left(2 \mathrm{H}, \mathrm{m}, \mathrm{H}_{\mathrm{a}}-1, \mathrm{H}_{\mathrm{b}}-1\right), 2.10(1 \mathrm{H}, \mathrm{m}, \mathrm{H}-4), 2.31$ $\left(1 \mathrm{H}, \mathrm{m}, \mathrm{H}_{\mathrm{b}}-2\right)$ and $2.41\left(1 \mathrm{H}, \mathrm{m}, \mathrm{H}_{\mathrm{a}}-2\right)$. 
$\beta$-sitosterone (2): (Syn. Sitosterone, $\beta$-stigmast-5-en3-one); Colorless gum; ${ }^{1} \mathrm{H}$ NMR (400 MHz, $\mathrm{CDCl}_{3}$ ): $\delta 0.86(3 \mathrm{H}, \mathrm{m}, \mathrm{Me}-27), 0.88(3 \mathrm{H}, \mathrm{d}, J=7.2 \mathrm{~Hz}, \mathrm{Me}-$ 26), $0.94(3 \mathrm{H}, \mathrm{t}, J=6.8 \mathrm{~Hz}, \mathrm{Me}-29), 0.99$ (3H, s, Me18), $0.99(3 \mathrm{H}, \mathrm{d}, J=6.00 \mathrm{~Hz}, \mathrm{Me}-21), 1.17(3 \mathrm{H}, \mathrm{s}$, Me-19) and 5.34 (1H, br. s, H-6).

Stigmasterol (3): (Syn. 33-Hydroxy-24-ethyl-5,22cholestadiene, 5,22-Stigmastadien-3 $\beta$-ol, Stigmasterin); Colorless gum; ${ }^{1} \mathrm{H}$ NMR (400 MHz, $\mathrm{CDCl}_{3}$ ): $\delta 0.68(3 \mathrm{H}, \mathrm{s}, \mathrm{Me}-13), 0.83(3 \mathrm{H}, \mathrm{t}, J=6.5 \mathrm{~Hz}, \mathrm{Me}-$ 28), $0.84(3 \mathrm{H}, \mathrm{d}, J=6.0 \mathrm{~Hz}, \mathrm{Me}-25), 0.91(3 \mathrm{H}, \mathrm{d}, J=$ $6.0 \mathrm{~Hz}, \mathrm{Me}-25), 0.92(3 \mathrm{H}, \mathrm{d}, J=6.8 \mathrm{~Hz}, \mathrm{Me}-20)$, $1.01(3 \mathrm{H}, \mathrm{s}, \mathrm{Me}-10), 3.52(1 \mathrm{H}, \mathrm{m}, \mathrm{H}-3), 5.01(1 \mathrm{H}, \mathrm{dd}$, $J=15.2,8.4 \mathrm{~Hz}, \mathrm{H}-23), 5.15(1 \mathrm{H}, \mathrm{dd}, J=15.2,8.8$ $\mathrm{Hz}, \mathrm{H}-22)$ and 5.35 (1H, m, H-6).

3,4-Dimethoxy-cis-caffeic acid (4): (Syn. 3,4Dimethoxy cinnamic acid) Pale yellow gum; ${ }^{1} \mathrm{H}$ NMR (400 MHz, $\mathrm{CDCl}_{3}$ ): $\delta 3.77$ (3H, s, OMe), 3.91 $(3 \mathrm{H}, \mathrm{s}, \mathrm{OMe}), 6.27(1 \mathrm{H}, \mathrm{d}, J=12.0 \mathrm{~Hz}, \mathrm{H}-8), 6.66$ $(1 \mathrm{H}, \mathrm{s}, \mathrm{H}-2), 6.81(1 \mathrm{H}, \mathrm{d}, J=8.5 \mathrm{~Hz}, \mathrm{H}-5), 6.88(1 \mathrm{H}$, $\mathrm{d}, J=8.5 \mathrm{~Hz}, \mathrm{H}-6)$ and $7.58(1 \mathrm{H}, \mathrm{d}, J=12.0 \mathrm{~Hz}$, H-7)

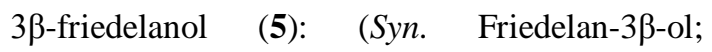
Epifriedelinol; 3 $\beta$-Hydroxyfriedelane; 3-Epifriedelinol; Epifriedelanol; Epifriedelal; Friedelin-3 $\beta$-ol); Colorless gum; 1H NMR (500 MHz, $\mathrm{CDCl}_{3}$ ): $\delta 0.80$ (3H, s, Me-25), 0.93 (3H, d, $J=6.8 \mathrm{~Hz}, \mathrm{Me}-23), 0.94$ (3H, s, Me-29), 0.96 (3H, s, Me-24), 0.98 (3H, s, Me26), 1.00 (3H, s, Me-30), 1.04 (3H, s, Me-27), 1.17 (3H, s, Me-28), $1.74(1 \mathrm{H}, \mathrm{dt}, J=12.8,3.2 \mathrm{~Hz}), 1.88$ $(1 \mathrm{H}, \mathrm{dt}, J=10.4,2.4 \mathrm{~Hz})$ and $3.73(\mathrm{H}-3, \mathrm{br} . \mathrm{s})$,

$\beta$-amyrone (6): (Syn. Olean-12-en-3-one); Colorless gum; ${ }^{1} \mathrm{H}$ NMR (500 MHz, $\mathrm{CDCl}_{3}$ ): $\delta 0.79$ $(3 \mathrm{H}, \mathrm{s}), 0.81(3 \mathrm{H}, \mathrm{s}), 0.82(3 \mathrm{H}, \mathrm{s}), 0.86(3 \mathrm{H}, \mathrm{s}), 0.88$ $(3 \mathrm{H}, \mathrm{s}), 0.92(3 \mathrm{H}, \mathrm{s}), 0.96(3 \mathrm{H}, \mathrm{s}), 1.01(3 \mathrm{H}, \mathrm{s}), 2.00$ $(1 \mathrm{H}, \mathrm{m}, \mathrm{H}-18), 2.24-2.30\left(1 \mathrm{H} \mathrm{x} 3, \mathrm{~m}, \mathrm{H}_{2}-2\right.$ and $\mathrm{H}_{\mathrm{a}}-$ $11)$ and $5.36(1 \mathrm{H}, \mathrm{t}, J=5.00 \mathrm{~Hz}, \mathrm{H}-12)$.

Glyceryl tricaprate (7): (Syn. 1,2,3Tricaprinoylglycerol, 1,2,3-Tridecanoylglycerol, Glycerol tricaprate, Glycerol tris(decanoate), Tricaprin, Tridecanoin); Colorless gum; ${ }^{1} \mathrm{H}$ NMR (500 MHz, $\left.\mathrm{CDCl}_{3}\right): \delta, 0.87\left(3 \times \mathrm{CH}_{3}, \mathrm{t}, J=6.5 \mathrm{~Hz}\right)$, $1.24\left(18 \times \mathrm{CH}_{2}, \mathrm{~s}\right), 1.59\left(3 \times \mathrm{CH}_{2}, \mathrm{~m}\right), 2.29\left(3 \times \mathrm{CH}_{2}\right.$, m), $4.14\left(2 \mathrm{H}, \mathrm{dd}, J=12.5,4.5 \mathrm{~Hz},-\mathrm{CH}_{2}-\right), 4.29(2 \mathrm{H}$, $\left.\mathrm{dd}, J=11.5,6.5 \mathrm{~Hz},-\mathrm{CH}_{2}-\right)$ and $5.34(1 \mathrm{H}, \mathrm{m},-\mathrm{CH}-)$.

\section{RESULTS AND DISCUSSION}

A total of seven compounds were isolated from the crude methanolic extract and its petroleum ether and dichloromethane soluble fractions of the stem bark of S. suaveolens by repeated chromatographic separation and purification over silica gel.

The structures of these compounds were elucidated as fridelin (1), $\beta$-sitosterone (stigmast-5en-3-one, 2), stigmasterol (3), 3,4-dimethoxy-ciscaffeic acid (4), $3 \beta$-friedelanol (5), $\beta$-amyrone (6) and glyceryl tricaprate (7) on the basis of analysis of spectral data and comparison of their ${ }^{1} \mathrm{H}$ NMR data with published values as well as co-TLC with authentic sample, whenever possible.

Compound 1 was obtained as colorless gum. The ${ }^{1} \mathrm{H}$ NMR spectrum $\left(400 \mathrm{MHz}, \mathrm{CDCl}_{3}\right.$ ) of compound 1 showed eight methyl group signals at $\delta 0.72,0.87$, $0.95,0.99,1.01,1.05,1.18$ and a unresolved doublet at $\delta 0.88(\mathrm{Me}-4)$. These were attributed to Me-5, Me-

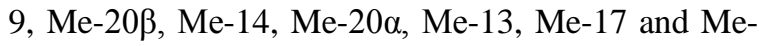
4 , respectively. The presence of eight methyl group signals was demonstrative of a triterpenoid type carbon skeleton. The absence of an oxymethine proton resonance around $\delta 3.0-3.5 \mathrm{ppm}$ suggested that $\mathrm{C}-3$ was ketonic rather than alcoholic. The above spectral features are in close agreement to those observed for fridelin. ${ }^{17}$ On the basis of the data , the identity of compound $\mathbf{1}$ has been established as fridelin and was substantiated by co-TLC with the reference sample.

The ${ }^{1} \mathrm{H}$ NMR spectrum (400 $\mathrm{MHz}, \mathrm{CDCl}_{3}$ ) of compound 2 showed the resonance of an olefinic proton at $\delta 5.34(1 \mathrm{H}$, br. s) for H-6. The signals for six methyls at $\delta \delta 0.86(3 \mathrm{H}, \mathrm{m}, \mathrm{Me}-27), 0.88(3 \mathrm{H}, \mathrm{d}, J$ $=7.2 \mathrm{~Hz}, \mathrm{Me}-26), 0.94(3 \mathrm{H}, \mathrm{t}, J=6.8 \mathrm{~Hz}, \mathrm{Me}-29)$, 0.99 (3H, s, Me-18), 0.99 (3H, d, $J=6.00 \mathrm{~Hz}, \mathrm{Me}-$ 21) and $1.17(3 \mathrm{H}, \mathrm{s}, \mathrm{Me}-19)$ were observed. Thus compound 2 was characterized as stigmast-5-en-3one ( $\beta$-sitosterone), the identity of which was further confirmed by comparison of its spectral data with literature values ${ }^{18}$ and with the spectral data of 
structurally-closed $\beta$-sitostenone $(\mathbf{8})^{19}$ as well as by co-TLC with the authentic sample.

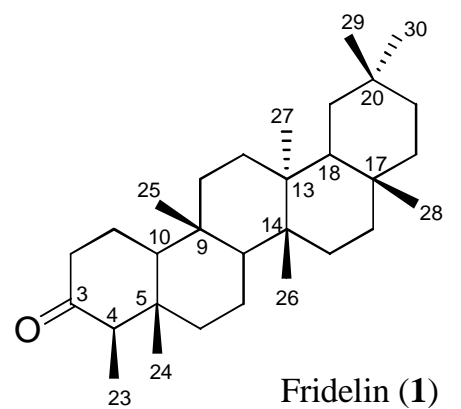<smiles>CCC(/C=C/C(C)C1CCC2C3CC=C4C[C@@H](O)CCC4(C)C3CCC12C)C(C)C</smiles>

Stigmasterol (3)<smiles>CC1C2CCC3C(C)(CCC4C5CC(C)(C)CCC5(C)CCC43C)C2CC[C@H]1O</smiles>

3ß-friedelanol (5)

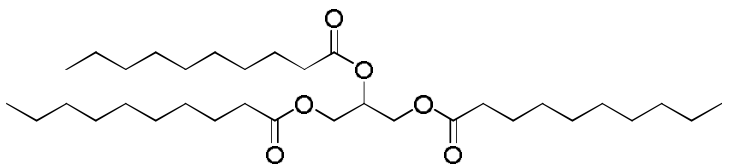

Glyceryl tricaprate (7)
Compound $\mathbf{3}$ was identified as stigmasterol by direct comparison of its ${ }^{1} \mathrm{H}$ NMR spectrum ${ }^{20}$ with that acquired for stigmasterol as well as by co- TLC.

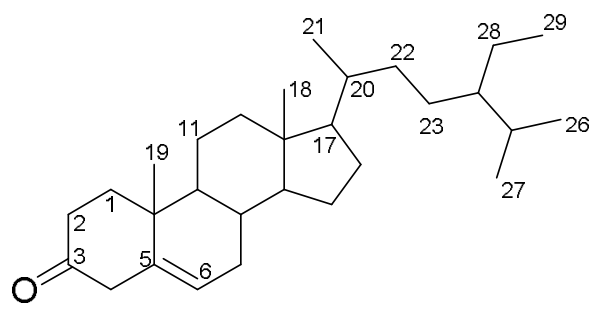

$\beta$-sitosterone (2)

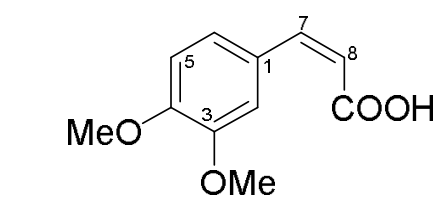

3,4-Dimethoxy cis-caffeic acid (4)
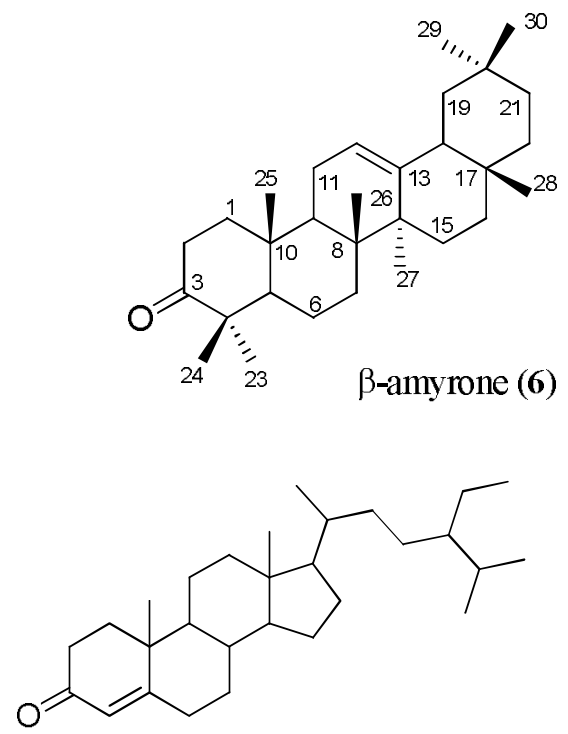

$\beta$-sitostenone (8)
Compound 4 was obtained as pale yellow gum. The ${ }^{1} \mathrm{H}$ NMR spectral (400 $\mathrm{MHz}, \mathrm{CDCl}_{3}$ ) data of compound 4 displayed signals for three aromatic protons, the splitting pattern and coupling constant of which indicated the presence of a 1,3,4-trisubstituted benzene ring. The aromatic proton $\mathrm{H}-2$ appeared as a broad singlet at $\delta 6.66$ while the other aromatic protons H-5 and H-6 appeared as doublets $(J=8.5$ 
$\mathrm{Hz}$ ) centered at $\delta 6.81$ and 6.88 , respectively. Additional singlets at $\delta 3.77$ and $\delta 3.91$ each of three proton intensity revealed the presence of two methoxy groups at C-3 and C-4 position of the aromatic ring. The olefinic protons, $\mathrm{H}-7$ and $\mathrm{H}-8$ appeared as doublets centered at $\delta 7.58$ and $\delta 6.27$, respectively with a $J$ value of $12.0 \mathrm{~Hz}$ which suggested that the olefinic protons are in cis configuration rather than trans $(J=15.9 \mathrm{~Hz})$. The relatively downfield resonance of $\mathrm{H}-7$ could be explained by its $\beta$-position to the carbonyl group. Therefore, compound 4 was characterized as 3,4dimethoxy-cis-caffeic acid. Its identity was further confirmed by comparison of its spectral data with literature values ${ }^{21}$ trans-caffeic acid, as well as coTLC with previously isolated sample.

The ${ }^{1} \mathrm{H}$ NMR spectrum $\left(500 \mathrm{MHz}, \mathrm{CDCl}_{3}\right.$ ) of compound 5 showed a pair of doublet of triplets centered at $\delta 1.88(1 \mathrm{H}, \mathrm{dt}, J=10.4,2.4 \mathrm{~Hz})$ and 1.74 $(1 \mathrm{H}, \mathrm{dt}, J=12.8,3.2 \mathrm{~Hz})$ which could be assigned to $\mathrm{H}_{\mathrm{a}}-2$ and $\mathrm{H}_{\mathrm{a}}-6$, respectively. The presence of a multiplet $\delta 3.73$ indicated an oxymethine proton at $\mathrm{H}-$ 3 position. The chemical shift and splitting pattern of this proton signal was typical for $3 \beta$-friedelanol-type triterpenoid skeleton. The ${ }^{1} \mathrm{H}$ NMR spectrum also showed a three proton doublet at $\delta 0.96\left(\mathrm{H}_{3}-23\right)$ and seven three proton singlets at $\delta 0.99\left(\mathrm{H}_{3}-24\right), 0.80$ $\left(\mathrm{H}_{3}-25\right), 0.99\left(\mathrm{H}_{3}-26\right), 1.04\left(\mathrm{H}_{3}-27\right), 1.17\left(\mathrm{H}_{3}-28\right)$, $0.96\left(\mathrm{H}_{3}-29\right)$ and $1.00\left(\mathrm{H}_{3}-30\right)$. On this basis, compound 5 was characterized as $3 \beta$-friedelanol, the identity of which was further confirmed by comparison of its spectral data with literature values ${ }^{22}$ as well as by co-TLC with the authentic sample.

${ }^{1} \mathrm{H}$ NMR spectrum $\left(500 \mathrm{MHz}, \mathrm{CDCl}_{3}\right)$ of compound 6 showed 8 three proton singlets at $\delta 0.79$, $0.81,0.82,0.88,0.86,0.92,0.96$ and $1.01(3 \mathrm{H} \mathrm{x} 8, \mathrm{~s}$, $8 \times \mathrm{Me})$. The spectrum revealed a multiplet at $\delta 2.24-$ $2.30(1 \mathrm{H} \mathrm{x} \mathrm{3,} \mathrm{m)} \mathrm{attributable} \mathrm{to} \mathrm{the} \mathrm{merged} \mathrm{signal} \mathrm{for}$ three protons of $\mathrm{H}_{2}-2$ and $\mathrm{H}_{\mathrm{a}}-11$. A one proton multiplet at $\delta 2.00$ was indicative of $\mathrm{H}-18$. The triplet at $\delta 5.36(J=5.00 \mathrm{~Hz})$ could be assigned to the lone olefinic proton at $\mathrm{H}-12$. The absence of the hydroxy proton signal at C-3, suggested compound 6 as $\beta$ amyrone. On this basis, compound 6 was characterized as $\beta$-amyrone, the identity of which was further supported by comparison of its spectral data with literature values. ${ }^{23}$

The ${ }^{1} \mathrm{H}$ NMR ( $500 \mathrm{MHz}, \mathrm{CDCl}_{3}$ ) signals between $\delta 0.87-2.31$ which indicated compound 7 as a fatty acid derivative. On the other hand, two double doublets with each of two protons intensity centered at $\delta 4.14\left(\mathrm{CH}_{2}, \mathrm{dd}, J=12.5,4.5 \mathrm{~Hz}\right)$ and $4.29\left(\mathrm{CH}_{2}\right.$, $\mathrm{dd}, J=11.5,6.5 \mathrm{~Hz}$ ) and another multiplet at $\delta 5.34$ $(\mathrm{CH}, \mathrm{s})$ suggested the presence of a glyceryl moiety. However, the downfield resonance of glycerol proton demonstrated that the moiety was esterified with appropriate fatty acid residues, because usually the characteristic doublet and multiplet for protons of free glycerol appear around $\delta 3.4-3.4$, respectively. A triplet with nine proton intensity at $\delta 0.87(3 \mathrm{x}$ $\mathrm{CH}_{3}, \mathrm{t}, J=6.5 \mathrm{~Hz}$ ), two multiplets with each of six protons intensity at $\delta 2.29\left(3 \times \mathrm{CH}_{2}, \mathrm{~m}\right)$ and $1.99(3 \mathrm{x}$ $\left.\mathrm{CH}_{2}, \mathrm{~m}\right)$ and an additional multiplet with 36 protons intensity at $\delta 1.24\left(18 \times \mathrm{CH}_{2}\right.$, s) indicated the presence of three capric acid (decanoic acid) moieties. Generally glycerol appears as triglycerides in nature. Thus, compound $\mathbf{7}$ was characterized as glyceryl tricaprate. ${ }^{24}$

\section{ACKNOWLEDGEMENT}

The authors thank the Department of Pharmacy, King's College London, United Kingdom for assisting with some NMR analysis of our samples.

\section{REFERENCES}

1. Troup, R.S. 1986. Silviculture of Indian Trees Volume 2: Leguminosae (Caesalpinieae) to Verbenaceae. International Book Distributors, Dehradun, India.

2. Binutu, O.A., Adesogan, K.E. and Okogun, J.I. 1996. Antibacterial and antifungal compounds from Kigelia pinnata. Planta Med. 62, 352-353.

3. Onegi, B., Kraft, C., Köhler, I, Freund, M., Jenett-Siems, K., Siems, K., Beyer, G., Melzig, M.F., Bienzle, U. and Eich, E. 2002. Antiplasmodial activity of naphthoquinones and one anthraquinone from Stereospermum kunthianum. Phytochemistry 60, 39-44.

4. Ghani, A. 1998. Medicinal Plants of Bangladesh: Chemical Constituents and Uses $1^{\text {st }}$ Edition, Asiatic Society of Bangladesh.

5. Yoganarasimhan, S.N. 2000. Medicinal plants of India, volume 2, Tamilnadu. 
6. Rao, K., McBride, T.J. and Oleson, J.J. 1968. Recognition and evaluation of lapachol as an antitumor agent, Cancer Res. 28,1952-1954.

7. Subramanian, S.S., Nagarajan, S. and Sulochana, M.N. 1972. Flavonoids of the leaves of Stererospermum suaveolens, Curr. Sci. 41, 102-103.

8. Sandermann, W. and Dietrichs, H.H. 1957. Untersuchungen über termitenresistente Hölzer. Holz. als. Roh-und. Werkstoff 15, 281-297.

9. Joshi, K.C., Bansal, R.K. and Patni, R. 1977. Chemical examination of the roots of Stereospermum suaveolens DC. J. Indian Chem. Soc., 54, 648-649.

10. Schulz, K.H., Garbe, I. and Hausen, B.M. 1977. Simatupang MH The sensitizing capacity of naturally occurring quinones. I. Naphthoquinones and related compounds. Arch. Dermatol. Forsch. 258, 41-52.

11. Haque, M.R., Rahman, K.M., Iskander, M.N., Hasan, C.M. and Rashid M.A. 2006. Stereochenols A and B, two quinines from Stereospermum chelonoides. Phytochemistry 67, 26632665.

12. Onegi, B., Kraft, C., Kohler, I., Freund, M., Jenett-Siems, K., Siems, K., Beyer, G., Melzig, M.F., Bienzle, U. and Eich, E., 2002. Antiplasmodial activity of naphthoquinones and one anthraquinone from Stereospermum kunthianum. Phytochemistry 60, 39-44.

13. Kumar, U.S., Kumar, P. Aparna, R.J., Rao, T.P. and Rao, J.M. 2003. 1-Methyl anthraquinones and their biogenetic precursors from Stereospermum personatum. Phytochemistry 63, 925-929.

14. Sikder, A.A., Sharmin, T., Rahman, A.F.M.M., Haque, M.R., Rahman, M.S. and Rashid, M.A. 2013. Screenings of four medicinal plants of Bangladesh for bioactivities. Dhaka Univ. J. Pharm. Sci. 12, 59-62.

15. Ara, K., Haque, M.R., Kaisar, M.A., Rahman, A.H.M.M., Hasan, C.M. and Rashid, M.A. 2012. A new diarylheptanoid from Garuga pinnata Roxb. Dhaka Univ. J. Pharm. Sci. 12, 165-167.
16. Venwagenen, B.C., Larsen, R., Cardellina, J.H.I.I., Randazzo, D., Lidert, Z.C., and Swithenbank, C. 1993. Ulosantoin, a potent insecticide from the sponge Ulosareutzleri. J. Org. Chem. 58, 335-337.

17. Gunatilaka, A.A.L, Nanayakkara, N.P.D. and Wazeer, M.I.M. 1983. ${ }^{13} \mathrm{C}$ NMR spectra of some D:A -friedo-oleananes. Phytochemistry 22, 991-992.

18. Cambie, R.C., Lal, A.R., Rutledge, P.S. and Woodgate, P.D. 1991. Ent-14[S],16ß,17-trihydroxyatisan-3-one and further constituents from Euphorbia fidjiana. Phytochemistry 30, 287-292.

19. Ara, K., Rahman, M.S., Rahman, A.H.M.M., Hasan, C.M. and Rashid, M.A. 2009. Terpenoids and coumarin from Bursera serrata Wall. Dhaka Univ. J. Pharm. Sci. 8, 107-110.

20. Khan, R.I. 1991. Natural product: A laboratory guide, $2^{\text {nd }}$ edition, Academic press, N.Y., USA.

21. Teng. R.W., Wang, D.Z., Wu, Y.S., Lu, Y., Zheng, Q,T. and Yang. C.R. 2005. NMR assignments and single-crystal X-ray diffraction analysis of deoxyloganic acid. Magn. Res. Chem. 43, 92-96

22. Almeida, M.F.O., Melo, A.C.R., Pinheiro, M.L.B., Silva, J.R.A., Souza, A.D.L., Barison, A., Campos, F.R., Amara, A.C.F., Machado, G.M.C. and Leon, L.L.P. 2011. Chemical constituents and leishmanicidal activity of Gustavia elliptica (Lecythidaceae). Quím. Nova 34, 1182-87.

23. Xiao-Dong L., Shao-Hua, W., Yun-Bao, M. and Da-Gang, W. 2001. Acta Botanica Sinica 43, 426-430.

24. Francisca Jofre, F., Anderson, M.E. and Markley, J.L. Madison Metabolomics Consortium(http://www.bmrb.wisc. edu/metabolomics/mol_summary/show_data.php?molName= glyceryl_tridecanoate\&id=bmse000566\& whichTab=1) 